OPEN ACCESS

Edited by:

Hong Ni,

Children's Hospital of Soochow

University, China

Reviewed by:

Robyn Blackford,

Ann \& Robert H. Lurie Children's

Hospital of Chicago, United States

Jianxiang Liao,

Shenzhen Children's Hospital, China

*Correspondence:

Yuwu Jiang

jiangyuwu@bjmu.edu.cn

Kai Gao

gaokaipku@bjmu.edu.cn

Specialty section:

This article was submitted to

Pediatric Neurology,

a section of the journal

Frontiers in Neurology

Received: 14 December 2021 Accepted: 27 December 2021

Published: 18 January 2022

Citation:

Lin $Z$, Sang T, Yang $Y, W u Y$, Dong $Y$,

Ji T, Zhang Y, Wu Y, Gao K and

Jiang Y (2022) Efficacy of Anti-seizure

Medications, Quinidine, and

Ketogenic Diet Therapy for

KCNT1-Related Epilepsy and

Genotype-Efficacy Correlation

Analysis. Front. Neurol. 12:834971.

doi: 10.3389/fneur.2021.834971

\section{Efficacy of Anti-seizure Medications, Quinidine, and Ketogenic Diet Therapy for KCNT1-Related Epilepsy and Genotype-Efficacy Correlation Analysis}

\author{
Zehong Lin 1,2,3, Tian Sang ${ }^{1,2,3}$, Ying Yang ${ }^{1,2,3}$, Yuan Wu ${ }^{1,2,3}$, Yan Dong ${ }^{4}$, Taoyun $\mathrm{Ji}^{1,2,3}$, \\ Yuehua Zhang ${ }^{1,2,3}$, Ye Wu ${ }^{1,2,3}$, Kai Gao ${ }^{1,2,3,5 *}$ and Yuwu Jiang ${ }^{1,2,3,5,6 *}$ \\ ${ }^{1}$ Department of Pediatrics, Peking University First Hospital, Beijing, China, ${ }^{2}$ Beijing Key Laboratory of Molecular Diagnosis \\ and Study on Pediatric Genetic Diseases, Beijing, China, ${ }^{3}$ Children Epilepsy Center, Peking University First Hospital, Beijing, \\ China, ${ }^{4}$ Department of Pediatrics, Third Affiliated Hospital of Zhengzhou University, Zhengzhou, China, ${ }^{5}$ Key Laboratory for \\ Neuroscience, Ministry of Education/National Health and Family Planning Commission, Peking University, Beijing, China, \\ ${ }^{6}$ Center of Epilepsy, Beijing Institute for Brain Disorders, Beijing, China
}

Aim: To evaluate the efficacy of anti-seizure medications (ASMs), quinidine, and ketogenic diet therapy (KDT) for KCNT1-related epilepsy and to explore genotype-efficacy correlations.

Methods: We collected the data for KCNT1-related epilepsy cases from our hospital's medical records and the literature. In total, 50 patients received quinidine, 23 received classical KDT, and 15 received ASMs; all ASM data were from our hospital owing to the lack of detailed ASM data in the literature. The efficacy rates (ERs) of the treatments were compared; an ER that reduced the number of seizures by $\geq 50 \%$ was considered positive. Efficacy according to genotype was also assessed.

Results: The ERs for the 30 patients at our hospital were 40, 26.7, 30, and 44.4\% for all treatments, ASMs, quinidine, and KDT, respectively. For all patients (ours and those in previous reports), the overall ERs for quinidine and KDT were 26.0 and 43.5\%, respectively $(P=0.135)$. The ERs for quinidine and KDT in functional domain variant-related epilepsy differed significantly (20.6 vs. $53.8 \%$; $P=0.037$ ).

Interpretation: KDT may be better at treating KCNT1-related epilepsy than quinidine; ASMs were the least effective. KDT is a viable treatment option for functional domain variant-related epilepsy.

Keywords: KCNT1, epilepsy, anti-seizure medications, quinidine, ketogenic diet

\section{INTRODUCTION}

KCNT1 encodes a $\mathrm{Na}^{+}$-activated $\mathrm{K}^{+}$channel named Slo2.2, Slack, or KCa4.1. Slo2.2 is the largest known $\mathrm{K}^{+}$channel and is mainly distributed in the frontal cortex of the brain (1). It consists of six transmembrane segments (S1-S6), with a pore domain between S5 and S6 and a cytoplasmic C-terminal domain $(2,3)$. The $\mathrm{C}$-terminal domain is the largest subunit of the channel, containing 
TABLE 1 | Patients with quinidine treatment (including our patients) $(5,12,15,16)$.

\begin{tabular}{|c|c|c|c|c|c|}
\hline Variant & Case number & Efficacy rate & Variant & Case number & Efficacy rate \\
\hline c.1193G >A, p.Arg398Gln & 5 & 0 & c.1955G> T, p.Gly652Val & 1 & $1 / 1$ \\
\hline c.1238G >A, p.Arg428Gln & 6 & $2 / 6$ & c.2386T>C, p.Tyr796His & 1 & 0 \\
\hline c.1420C>T, p.Arg474Cys & 1 & 0 & c.2786G >A, p.Arg929Gln & 1 & 0 \\
\hline c. $1421 \mathrm{G}>\mathrm{A}, \mathrm{p}$. Arg474His & 7 & 0 & c.2795T>C, p.Phe932Ser & 1 & $1 / 1$ \\
\hline c.1429G >A, p.Ala477Thr & 2 & $1 / 2$ & c.2800G >A, p.Ala934Thr & 5 & $1 / 5$ \\
\hline c.1438G >A, p.Asp480Asn & 1 & 0 & c.2839A>G, p.Lys947Glu & 1 & 0 \\
\hline c.1546A>G, p.Met516Val & 1 & 0 & c.2849G >A, p.Arg950Gln & 3 & $2 / 3$ \\
\hline c.2881C>A, p.Arg961Ser & 1 & $1 / 1$ & c.776 C>A, pAla259Asp & 1 & 0 \\
\hline c.2882G >A, p.Arg961His & 1 & 0 & c. $808 \mathrm{C}>\mathrm{G}$, p.Gln270Glu & 1 & 0 \\
\hline c.862G >A, p.Gly288Ser & 10 & $4 / 10$ & & & \\
\hline
\end{tabular}

regulators of $\mathrm{K}^{+}$conductance (RCKs) and a nicotinamide adenine dinucleotide-binding domain. These subunits exist in the form of tetramers and mediate the channel's allosteric regulation by ligands $(2,3)$.

Recent studies identified KCNT1 as a novel driver of pathogenesis in some types of refractory epilepsy (e.g., epilepsy of infancy with migrating focal seizures, autosomal dominant nocturnal frontal lobe epilepsy, West syndrome, Ohtahara syndrome, early myoclonic encephalopathy, focal epilepsy, and multifocal epilepsy) (4-6). However, these diseases are generally highly resistant to traditional anti-seizure medications (ASMs), and the optimal treatment strategy for KCNT1-related epilepsy has yet to be determined (5). Because Slo.2.2 is $\mathrm{Na}^{+}$-activated, it can be inactivated by $\mathrm{Na}^{+}$blockers such as quinidine. The efficacy of quinidine on KCNT1-related epilepsy has been examined in many studies but remains controversial (7-12).

Ketogenic diet therapy (KDT) for refractory epilepsy has recently received increasing attention. The ketogenic diet is a high-fat, low-carbohydrate diet; according to previous reports, it controls seizures by regulating glycolysis, mitochondrial metabolism, neuronal transmission, polyunsaturated fatty acid levels, and other cellular mechanisms $(13,14)$ and effectively treats KCNT1-related epilepsy (5).

Therefore, we hypothesized that KDT would better control KCNT1-related epilepsy than do ASMs and quinidine. To test this hypothesis, we compared the efficacy of these treatments by retrospectively analyzing the outcomes of patients with KCNT1-related epilepsy at our institution and in the literature. The effect of the KCNT1 genotype on efficacy was also explored.

Therefore, in this study, we evaluated the efficacy of ASMs, quinidine, and KDT in KCNT1-related epilepsy. Further, we explored the efficacy-genotype correlations of KCNT1-related epilepsy based on data of our patients and patients reported in the literature.

Abbreviations: ASM, anti-seizure medication; ER, efficacy rate; KDT, ketogenic diet therapy; RCK, regulator of $\mathrm{K}^{+}$conductance.

\section{METHODS}

\section{Participants}

We collected 30 patients with KCNT1-related epilepsy treated at our hospital. Detailed clinical data, including age at onset, seizure type, diagnosis, neurologic and cognitive deficits, treatment (ASMs, KDT, quinidine), and genotype, were collected from patient records. This study was approved by the Medical Ethics Committee of Peking University First Hospital (Approval Number: IRB00001052-17030). Written informed consent to participate in this study and for publication of the results was obtained from the guardians of all patients.

We also reviewed all previously published cases in which patients received quinidine $(n=40)(5,12,15,16)$ or KDT $(n=14)(5,12)$ for treatment of KCNT1-related epilepsy, with clear efficacy results. The total number of patients (ours and those in the literature) who received quinidine was 50 (Table 1) and the total number who received KDT was 23 (Table 2). All these patients had received more than at least 3 ASMs before either quinidine or KDT treatment which meaned they were the drug-resistant. Owing to the lack of detailed ASM data in previously reported cases, we used the data from 15 patients from our hospital records who had treated only by ASMs to analyze the efficacy of ASM in KCNT1-related epilepsy. The genotype distribution is shown in the Figure 1, and the analysis of efficacy is shown in Table 3.

\section{Statistical Analysis}

Median patient age, age at onset, genetic testing results, disease duration, and the efficacy rates (ERs) for ASMs, quinidine, and KDT were considered as descriptive variables. Fisher's exact test and the chi-square test were used to compare the efficacy of quinidine and KDT in patients stratified and not stratified, respectively, according to the location of the KCNT1 mutation. Antiepileptic treatment was considered effective if it reduced the occurrence of seizures by $\geq 50 \%$. $P$-values $<0.05$ were considered statistically significant. Statistical analyzes were performed using SPSS for Windows version 26.0 (IBM Corp., Armonk, NY, USA). 
TABLE 2 | Patients with KDT (including our patients) (5, 12).

\begin{tabular}{|c|c|c|c|c|c|}
\hline Variant & Case number & Efficacy rate & Variant & Case number & Efficacy rate \\
\hline c.1066C>T,p.Arg356Trp & 1 & $1 / 1$ & c.2885T>C,p.Leu962Pro & 1 & 0 \\
\hline c.1193G > A p.Arg398Gln & 1 & 0 & c.776 C>A,pAla259Asp & 1 & 0 \\
\hline c.1225C>T,p.Pro409Ser & 1 & $1 / 1$ & c.808C > G,p.Gln270Glu & 1 & 0 \\
\hline c.1283G > A,p.Arg428Gln & 1 & $1 / 1$ & c.820C >A,p.Leu274lle & 1 & $1 / 1$ \\
\hline c. $1421 \mathrm{G}>$ A,p.Arg474His & 2 & $1 / 2$ & c.862G > A p.Gly288Ser & 5 & $3 / 5$ \\
\hline c. $1438 \mathrm{G}>$ A,p.Asp480Asn & 1 & 0 & c.2800G >A,p.Ala934Thr & 4 & $1 / 4$ \\
\hline c. $1885 A>$ a,p.Lys629Glu & 1 & 0 & c.2849G >A,p.Arg950Gln & 2 & $1 / 2$ \\
\hline
\end{tabular}
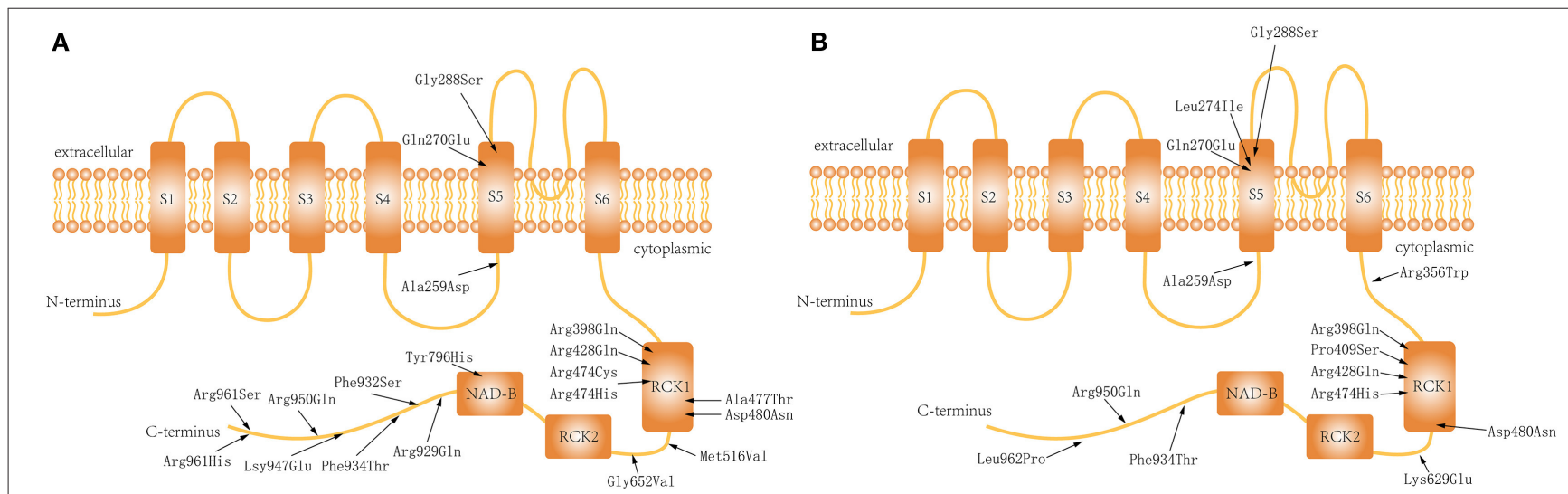

FIGURE 1 | Distribution of the variations in the Slo2.2 channel: (A) Patients who received quinidine treatment. (B) Patients who underwent ketogenic diet therapy.

\section{RESULTS}

Data were collected from 30 patients treated for KCNT1-related epilepsy at our hospital [17 boys and 13 girls; age at onset, 1.25 (0.04-36) months]. All patients had features of developmental and epileptic encephalopathy, and their epilepsy treatments included ASMs, quinidine, and KDT. The ER for all epilepsy treatments was $40 \%$; the ERs for ASMs, quinidine, and KDT were $26.7 \%$ (4/15), 30\% (3/10), and 44.4\% (4/9), respectively. One patient received both KDT and quinidine, which was effective. Clinical data are shown in Table 4.

Fifty patients, including those at our hospital and in previous reports, received quinidine, with an overall ER of $26.0 \%(13 / 50)$. The ERs for non-functional vs. functional domain variant-related epilepsy (37.5 vs. $20.6 \%$ ) were not significantly different, nor were those for transmembrane vs. non-transmembrane domain variant-related epilepsy (36.4 vs. 23.1\%). The ERs for RCK1 and non-RCK1 domain variant-related epilepsy were 13.6 and $35.7 \%$, respectively, and this difference was of borderline significance $(P$ $=0.077)$.

Twenty-three patients, including those at our hospital and in previous reports, received KDT, with an overall ER of $43.5 \%$ $(10 / 23)$. There was no significant difference in the ERs for nonfunctional vs. functional ( 53.8 vs. $30 \%$ ), RCK1 vs. non-RCK1 (50 vs. $41.2 \%)$, or transmembrane vs. non-transmembrane (57.1 vs. and $37.5 \%$ ) domain variant-related epilepsy.
TABLE 3 | Efficacy of quinidine and ketogenic diet in the treatment of KCNT1-related epilepsy.

\begin{tabular}{|c|c|c|c|}
\hline & $\begin{array}{l}\text { Function domain } \\
\text { (S5, RCK, NAD-B) }\end{array}$ & Non-function domain & $P$-value \\
\hline Quinidine & $20.6 \%(7 / 34)$ & $37.5 \%(6 / 16)$ & 0.301 \\
\hline Ketogenic diet & $53.8 \%(7 / 13)$ & $30 \%(3 / 10)$ & 0.402 \\
\hline \multirow[t]{2}{*}{$P$-value } & 0.037 & 1.000 & - \\
\hline & RCK1 & Non-RCK1 & $\boldsymbol{P}$-value \\
\hline Quinidine & $13.6 \%(3 / 22)$ & $35.7 \%(10 / 28)$ & 0.077 \\
\hline Ketogenic diet & $50 \%(3 / 6)$ & $41.2 \%(7 / 17)$ & 1.000 \\
\hline \multirow[t]{2}{*}{$P$-value } & 0.091 & 0.714 & - \\
\hline & $\begin{array}{c}\text { Transmembrane } \\
\text { domain }\end{array}$ & Non-transmembrane & $P$-value \\
\hline Quinidine & $36.4 \%(4 / 11)$ & $23.1 \%(9 / 39)$ & 0.445 \\
\hline Ketogenic diet & $57.1 \%(4 / 7)$ & $37.5 \%(6 / 16)$ & 0.650 \\
\hline$P$-value & 0.630 & 0.326 & - \\
\hline
\end{tabular}

Finally, we compared the clinical efficacy of quinidine and KDT for treating KCNT1-related epilepsy. The overall ER was higher for KDT than for quinidine (43.5 vs. $26.0 \%$; $P=0.135$ ), as was the ER for RCK1 domain variant-related epilepsy (50 vs. 13.6\%; $P=0.091$ ); however, neither difference was significant. The ER for functional domain variant-related epilepsy was 
TABLE 4 | Treatments.

\begin{tabular}{|c|c|c|c|c|c|}
\hline Case & Total ASMs tried & $\begin{array}{l}\text { Quinidine therapy; when; } \\
\text { maximum dose (mg/kg.d); } \\
\text { effective } \text {; drug working time } \\
\text { (mo); effective duration (mo) }\end{array}$ & $\begin{array}{l}\text { Quinidine side } \\
\text { effect }\end{array}$ & $\begin{array}{l}\text { KDT; when; effective }{ }^{a} \text { KDT } \\
\text { working time (mo); effective } \\
\text { duration (mo) }\end{array}$ & KDT side effect \\
\hline 1 & TPM, LEV, PB & Not tried & - & Not tried & - \\
\hline 2 & $\begin{array}{l}\text { VPA, TPM, LEV, PB, OXC, } \\
\text { NZP, LCM, CLB* }\end{array}$ & Not tried & - & Not tried & - \\
\hline 3 & LEV, OXC, CLB, VPA*, CZP* & $\begin{array}{l}\text { Y; } 13 \text { mo after onset; 6; Y; 0.25; } \\
6\end{array}$ & emesis & Y; 6 mo after onset; nil; nil; nil & $\begin{array}{l}\text { Emesis, } \\
\text { constipation }\end{array}$ \\
\hline 4 & $\begin{array}{l}\text { TPM, LEV, OXC, CZP, LCM, } \\
\text { PB, VPA }\end{array}$ & $\begin{array}{l}\text { Y; } 1.5 \text { mo after onset; 12.5; nil; } \\
\text { nil; nil }\end{array}$ & $\begin{array}{l}\text { QT internal } \\
\text { prolongation }\end{array}$ & Y; 2 mo after onset; Y 2; 0.5 & Emesis, diarrhea \\
\hline 5 & $\begin{array}{l}\text { TPM, LTG, CBZ, OXC, VGB, } \\
\text { CLB, VPA*, LEV*, CZP*, }\end{array}$ & $\begin{array}{l}\text { Y; } 36 \text { mo after onset; 33; Y; 0.11; } \\
3\end{array}$ & None & Not tried & - \\
\hline 6 & $\begin{array}{l}\text { OXC, VPA, CZP, TPM, LEV, } \\
\text { PB }\end{array}$ & Not tried & - & Not tried & - \\
\hline 7 & $\begin{array}{l}\text { VPA, LTG, VPA, TPM, LEV, } \\
\text { LTG, OXC }\end{array}$ & $\begin{array}{l}\text { Y; } 48 \text { mo after onset; 16.7; nil; } \\
\text { nil; nil }\end{array}$ & Abnormal ECG & Y; 36 mo after onset; nil; nil; nil & Constipation \\
\hline 8 & VPA, TPM, LTG, CZP, & $\begin{array}{l}\text { Y; } 11 \text { mo after onset; 9; Y; 0.50; } \\
3\end{array}$ & Anorexia & Y; 11 mo after onset; $Y ; 0.50 ; 3$ & Feeding difficulties \\
\hline 9 & $\begin{array}{l}\text { VPA, TPM, LEV, LTG, PB, } \\
\text { OXC, Zonisamide, VGB* }\end{array}$ & $\begin{array}{l}\text { Y; } 17 \text { mo after onset;15; nil; nil; } \\
\text { nil }\end{array}$ & No side effect & Y; 3 mo after onset; nil; nil; nil & Feeding difficulties \\
\hline 10 & TPM, LEV, PB & Not tried & - & Not tried & - \\
\hline 11 & TPM, LEV, PB & Not tried & - & Not tried & - \\
\hline 12 & LEV, ACTH, TPM, LTG, PB & Not tried & - & Not tried & - \\
\hline 13 & VPA, TPM, PB, LEV* & Y; 5 mo after onset; 7; nil; nil; nil & abnormal ECG & Not tried & - \\
\hline 14 & $\begin{array}{l}\text { TPM, LTG, CBZ, OXC, CLB, } \\
\text { VGB, LCM, VPA*, } \\
\text { LEV* }^{*}, C^{*}\end{array}$ & Not tried & - & Not tried & - \\
\hline 15 & TPM, LEV, PB, OXC, CZP* & Y; 3 mo after onset;2; Y; 1; 30; & No side effect & Not tried & - \\
\hline 16 & VPA, TPM, PB, LEV & Not tried & - & Not tried & - \\
\hline 17 & $\begin{array}{l}\text { LEV, TPM, CBZ, PB, OXC, } \\
\text { CZP, VGB, CLB, ilepcimide }\end{array}$ & Not tried & - & Y; NA; nil; nil; nil & NA \\
\hline 18 & $\begin{array}{l}\text { TPM, LEV, LTG, CBZ, OXC, } \\
\text { VPA* }^{*}\end{array}$ & Not tried & - & Not tried & - \\
\hline 19 & $\begin{array}{l}\text { Acetazolamide, LEV, CBZ, } \\
\text { VPA, TPM }\end{array}$ & $\begin{array}{l}\text { Y; } 2.5 \text { mo after onset; 33; nil; nil; } \\
\text { nil }\end{array}$ & No side effect & Y; 3.5 mo after onset; Y; 3; 26 & Low energy \\
\hline 20 & $\begin{array}{l}\text { TPM, LEV, Acetazolamide, } \\
\text { OXC, VPA* }\end{array}$ & Not tried & - & Y; 3 mo after onset; nil; nil; nil & NA \\
\hline 21 & VPA, LEV, LTG, OXC, CZP & $\begin{array}{l}\text { Y; } 60 \text { mo after onset; NA; nil; nil; } \\
\text { nil }\end{array}$ & No side effect & Not tried & - \\
\hline 22 & $\begin{array}{l}\text { VPA, TPM, LTG, PB, OXC, } \\
\text { CZP }\end{array}$ & Not tried & - & Not tried & - \\
\hline 23 & $\begin{array}{l}\text { VPA, LEV, CZP, OXC* } \\
\text { VGB }^{*}, \text { CLB }^{*}\end{array}$ & Not tried & - & Not tried & - \\
\hline 24 & VPA, LEV, TPM & Not tried & - & Not tried & - \\
\hline 25 & LEV, VPA, TPM & Not tried & - & Not tried & - \\
\hline 26 & $\begin{array}{l}\text { Glucocorticoid, PB, OXC, } \\
\text { TPM, VPA }\end{array}$ & Not tried & - & Not tried & - \\
\hline 27 & $\begin{array}{l}\text { LEV, OXC, TPM, VPA*, } \\
\text { VGB }^{*}\end{array}$ & Y; 4 mo after onset; 39; nil; nil; nil & $\begin{array}{l}\text { Seizures } \\
\text { worsened, QT } \\
\text { internal } \\
\text { prolongation }\end{array}$ & Not tried & - \\
\hline 28 & $\begin{array}{l}\text { LEV, LTG, OXC, VPA, TPM, } \\
\text { LCM }\end{array}$ & Not tried & - & Not tried & - \\
\hline 29 & $\begin{array}{l}\text { TPM, LEV, LCM*, } \\
\text { PeraMpanel* }\end{array}$ & Not tried & - & Y; 6 mo after onset; Y; $0.25 ; 0.25$ & Feeding difficulties \\
\hline 30 & VPA, LEV, OXC, TPM ${ }^{*}$ & Not tried & - & Y; NA; Y; NA; NA & NA \\
\hline
\end{tabular}

${ }^{a}$ Effective: Seizure reduction $\geq 50 \%$.

*Effective; mo, month; Y, Yes; NA, not applicable; VPA, Valproate; TPM, Topamax; LEV, Levetiracetam; LTG, Lamotrigine; CBZ, Carbamazepine; OXC, Oxcarbazepine; CZP, Clonazepam; NAP, Nitrazepam; PB, Phenobarbital; CLB, Clobazam; VGB, Vigabatrin; LCM, Lacosamide; ACTH, Adrenocorticotropic hormone; KDT, Ketogenic diet therapy; Os, ongoing seizures; ECG, Electrocardiograph. 
significantly higher for KDT than for quinidine (53.8 vs. $20.6 \%$; $P=0.037)$. No significant difference was observed between the ERs for KDT and quinidine for non-functional (30.0 vs. $37.5 \%$; $P$ $=1.000$ ), non-RCK1 (41.2 vs. $35.7 \% ; P=0.714)$, transmembrane (57.1 vs. $36.4 \%$; $P=0.630$ ), or non-transmembrane (37.5 vs. $23.1 \%$; $P=0.326)$ domain variant-related epilepsy.

\section{DISCUSSION}

This study compared the efficacy of ASMs, quinidine, and KDT on KCNT1-related epilepsy treatment. Our results suggest that KDT may be a more effective treatment than is quinidine, whereas ASMs are the least effective.

Many studies have shown that quinidine effectively inhibits the electrical activity of Slo2.2 channels by blocking $\mathrm{Na}^{+}$ influx into cells (17-19); however, its clinical efficacy remains controversial (7-12). In this study, the overall ER for quinidine for KCNT1-related epilepsy was $\sim 26.0-30.0 \%$, indicating that not all patients with seizures benefit from quinidine treatment. Because the ER was based on combined quinidine and ASM treatment, we speculate that it may be worse for quinidine alone. Quinidine may indirectly control epilepsy by inhibiting the $\mathrm{Na}^{+}$ion driving effect of the Slo2.2 channel, which reduces $\mathrm{Na}^{+}$permeability. In this study, it was more effective for nonfunctional than for functional domain variant-related epilepsy, suggesting that mutations in the functional domain directly enhance $\mathrm{K}^{+}$channel activity, and therefore, that the response to $\mathrm{Na}^{+}$blockers was indirect and not obvious.

KDT was formally introduced as an epilepsy treatment in the twentieth century. It has become a commonly accepted treatment for drug-resistant epilepsy owing to its safety and few adverse reactions. In this study, the overall ER for KDT for KCNT1related epilepsy was $43.5-44.4 \%$, which was much higher than that for quinidine and ASMs. According to feedback from the parents of children undergoing KDT, feeding difficulties are the most common problems in the treatment process. Feeding difficulties can directly affect the concentration of ketone bodies in the body; therefore, we believe that the true efficacy of KDT may be higher than the current result.

We found that KDT was more effective in patients with functional vs. non-functional domain-variant related epilepsy, but uniformly effective in patients with other types of domain variant-related epilepsy. Unsaturated free fatty acids have been reported to increase the activity of $\mathrm{Ca}^{+}$-activated $\mathrm{K}^{+}$channels, thereby reducing the excitability of neurons (20). Thus, KDT may inhibit Slo2.2 channel activity via its effects on the levels of unsaturated fatty acids. Owing to their inhibitory effects on $\mathrm{Na}^{+}$channels, unsaturated fatty acids in ketogenic diets may impede $\mathrm{Na}^{+}$ion binding and the opening of Slo.2.2 channels, thus helping to manage epilepsy $(21,22)$. The biological mechanism of KDT is complex, multifaceted, and remains unclear; however, it may involve the combined actions of a variety of mechanisms. Hence, KDT potentially has a higher ER for KCNT1-related epilepsy.

In this study, KDT seems to have a significantly higher efficacy for KCNT1-related epilepsy than did ASMs and quinidine.
Compared with quinidine, KDT was equally effective and more effective for non-functional and non-functional domain variantrelated epilepsy, respectively. This result suggests that KDT is generally effective for all types of variant-related epilepsy, especially functional domain variant-related epilepsy; therefore, its mechanisms may be diverse. It also supports the use of quinidine for treatment of non-functional domain variantrelated epilepsy.

This study had some limitations. Because it was retrospective, some clinical data were missing and the efficacy evaluation process was not always sufficiently detailed. We plan to perform a more detailed analysis in the future. In addition, not all results were statistically significant, although a tendency toward significance was noted in some instances. The lack of significance may reflect the limited number of cases; thus, more cases need to be accumulated to test the validity of our results.

\section{CONCLUSION}

We evaluated the efficacy of ASMs, KDT, and quinidine for treating KCNT1-related epilepsy. KDT may be more effective than is quinidine and thus the more suitable treatment, whereas the efficacy of ASMs was poor. KDT and quinidine confer different therapeutic advantages depending on the KCNT1 variant: KDT was effective regardless of the variant and especially effective in patients with functional domain variantrelated epilepsy, whereas quinidine was effective in patients with non-functional domain variant-related epilepsy. Clarifying the relationship between genotype and curative effect will help optimize treatments and improve outcomes in KCNT1-related epilepsy in clinical practice.

\section{DATA AVAILABILITY STATEMENT}

The original contributions presented in the study are included in the article/supplementary material, further inquiries can be directed to the corresponding authors.

\section{ETHICS STATEMENT}

The studies involving human participants were reviewed and approved by Medical Ethics Committee of Peking University First Hospital. Written informed consent to participate in this study was provided by the participants' legal guardian/next of kin. Written informed consent was obtained from the individual(s) for the publication of any potentially identifiable images or data included in this article.

\section{AUTHOR CONTRIBUTIONS}

YJ and KG: study design, analysis, and revision of the manuscript. ZL and YY: follow-up of patient's information. ZL, TS, and YuW: draft preparation. ZL, TJ, YD, YZ, YeW, KG, and YJ: collection of clinical and WES data. All authors contributed to the article and approved the submitted version. 


\section{FUNDING}

This work was supported by the National Natural Science Foundation of China (Grant Numbers: 82171435, 81971211, 12026606, and 81601131), by Beijing Natural Science Foundation (Grant Number: 7212109), by the National Key Research and Development Program of China (Grant Numbers: 2020YFA0804000 and 2020YFA0804003), by the Beijing Key Laboratory of Molecular Diagnosis and Study on Pediatric

\section{REFERENCES}

1. Bhattacharjee A, Gan L, Kaczmarek LK. Localization of the Slack potassium channel in the rat central nervous system. J Comp Neurol. (2002) 454:24154. doi: 10.1002/cne.10439

2. Hite RK, MacKinnon R. Structural titration of Slo2.2, a $\mathrm{Na}(+)$-dependent $\mathrm{K}(+)$ channel. Cell. (2017) 168:390-99.e11. doi: 10.1016/j.cell.2016.12.030

3. Kaczmarek LK. Slack, slick, and sodium-activated potassium channels. ISRN Neuroscience. (2013) 2013:1-14. doi: 10.1155/2013/354262

4. Lim CX, Ricos MG, Dibbens LM, Heron SE. KCNT1mutations in seizure disorders: the phenotypic spectrum and functional effects. JMed Genet. (2016) 53:217-25. doi: 10.1136/jmedgenet-2015-103508

5. Borlot F, Abushama A, Morrison-Levy N, Jain P, Puthenveettil Vinayan K, Abukhalid M, et al. KCNT1-related epilepsy: an international multicenter cohort of 27 pediatric cases. Epilepsia. (2020) 61:679-92. doi: 10.1111/epi.16480

6. Martin HC, Kim GE, Pagnamenta AT, Murakami Y, Carvill GL, Meyer E, et al. Clinical whole-genome sequencing in severe early-onset epilepsy reveals new genes and improves molecular diagnosis. Hum Mol Genet. (2014) 23:320011. doi: $10.1093 / \mathrm{hmg} / \mathrm{ddu} 030$

7. Yoshitomi S, Takahashi Y, Yamaguchi T, Oboshi T, Horino A, Ikeda $\mathrm{H}$, et al. Quinidine therapy and therapeutic drug monitoring in four patients with KCNT1 mutations. Epileptic Disord. (2019) 21:48-54. doi: 10.1684/epd.2019.1026

8. Bearden D, Strong A, Ehnot J, DiGiovine M, Dlugos D, Goldberg EM. Targeted treatment of migrating partial seizures of infancy with quinidine. Ann Neurol. (2014) 76:457-61. doi: 10.1002/ana.24229

9. Fukuoka M, Kuki I, Kawawaki H, Okazaki S, Kim K, Hattori Y, et al. Quinidine therapy for west syndrome with KCNTI mutation: a case report. Brain Dev. (2017) 39:80-3. doi: 10.1016/j.braindev.2016.08.002

10. Jia Y, Lin Y, Li J, Li M, Zhang Y, Hou Y, et al. Quinidine therapy for lennoxgastaut syndrome with KCNT1 mutation. A case report and literature review. Front Neurol. (2019) 10:64. doi: 10.3389/fneur.2019.00064

11. Madaan P, Jauhari P, Gupta A, Chakrabarty B, Gulati S. A quinidine non responsive novel KCNT1 mutation in an Indian infant with epilepsy of infancy with migrating focal seizures. Brain Dev. (2018) 40:22932. doi: 10.1016/j.braindev.2017.09.008

12. Numis AL, Nair U, Datta AN, Sands TT, Oldham MS, Patel A, et al. Lack of response to quinidine in KCNT1-related neonatal epilepsy. Epilepsia. (2018) 59:1889-98. doi: 10.1111/epi.14551

13. Longo R, Peri C, Cricri D, Coppi L, Caruso D, Mitro N, et al. Ketogenic diet: a new light shining on old but gold biochemistry. Nutrients. (2019) 11:497. doi: 10.3390/nu11102497

14. Ulamek-Koziol M, Czuczwar SJ, Januszewski S, Pluta R. Ketogenic diet and epilepsy. Nutrients. (2019) 11:2510. doi: 10.3390/nu11102510

15. Fitzgerald MP, Fiannacca M, Smith DM, Gertler TS, Gunning B, Syrbe S, et al. Treatment responsiveness in KCNT1-related epilepsy.
Genetic Diseases (Grant Number: BZ0317), and by the Fundamental Research Funds for the Central Universities (Grant Numbers: BMU2017JI002, BMU2018XY006, PKU2017LCX06, and BMU2020MX029).

\section{ACKNOWLEDGMENTS}

We sincerely thank the patients' families for their kind support during the study.

Neurotherapeutics. (2019) 16:848-57. doi: 10.1007/s13311-019-00 739-y

16. Abdelnour E, Gallentine W, McDonald M, Sachdev M, Jiang YH, Mikati MA. Does age affect response to quinidine in patients with KCNT1 mutations? Report of three new cases and review of the literature. Seizure. (2018) 55:13. doi: 10.1016/j.seizure.2017.11.017

17. Yang B, Gribkoff VK, Pan J, Damagnez V, Dworetzky SI, Boissard CG, et al. Pharmacological activation and inhibition of Slack (Slo22) channels. Neuropharmacology. (2006) 51:896906. doi: 10.1016/j.neuropharm.2006.06.003

18. Mikati MA, Jiang YH, Carboni M, Shashi V, Petrovski S, Spillmann R, et al. Quinidine in the treatment of KCNT1-positive epilepsies. Ann Neurol. (2015) 78:995-9. doi: 10.1002/ana.24520

19. Rizzo F, Ambrosino P, Guacci A, Chetta M, Marchese G, Rocco T, et al. Characterization of two de novoKCNT1 mutations in children with malignant migrating partial seizures in infancy. Mol Cell Neurosci. (2016) 72:54-63. doi: 10.1016/j.mcn.2016.01.004

20. Denson DD, Wang X, Worrell RT, Eaton DC. Effects of fatty acids on BK channels in GH(3) cells. Am J Physiol Cell Physiol. (2000) 279:C12119. doi: 10.1152/ajpcell.2000.279.4.C1211

21. Vreugdenhil M, Bruehl C, Voskuyl RA, Kang JX, Leaf A, Wadman WJ. Polyunsaturated fatty acids modulate sodium and calcium currents in CA1 neurons. Proc Natl Acad Sci USA. (1996) 93:12559-63. doi: 10.1073/pnas.93.22.12559

22. Xiao YF, Ma L, Wang SY, Josephson ME, Wang GK, Morgan JP, et al. Potent block of inactivation-deficient $\mathrm{Na}+$ channels by $\mathrm{n}-3$ polyunsaturated fatty acids. Am J Physiol Cell Physiol. (2006) 290:C36270. doi: 10.1152/ajpcell.00296.2005

Conflict of Interest: The authors declare that the research was conducted in the absence of any commercial or financial relationships that could be construed as a potential conflict of interest.

Publisher's Note: All claims expressed in this article are solely those of the authors and do not necessarily represent those of their affiliated organizations, or those of the publisher, the editors and the reviewers. Any product that may be evaluated in this article, or claim that may be made by its manufacturer, is not guaranteed or endorsed by the publisher.

Copyright (c) 2022 Lin, Sang, Yang, Wu, Dong, Ji, Zhang, Wu, Gao and Jiang. This is an open-access article distributed under the terms of the Creative Commons Attribution License (CC BY). The use, distribution or reproduction in other forums is permitted, provided the original author(s) and the copyright owner(s) are credited and that the original publication in this journal is cited, in accordance with accepted academic practice. No use, distribution or reproduction is permitted which does not comply with these terms. 